\title{
Therapy of chronic graft-versus-host disease
}

\author{
Mukta Arora, MD, MS [Assistant Professor] ${ }^{*}$ \\ Division of Hematology, Oncology and Transplantation, University of Minnesota, Mayo Mail Code \\ 480, 420 Delaware Street SE, Minneapolis, MN 55455, USA
}

\begin{abstract}
Chronic graft-versus-host disease (cGVHD) is a common complication after hematopoietic-cell transplant and remains the leading cause of late non-relapse mortality. Standard treatment includes a combination of a calcineurin inhibitor and corticosteroids. Prolonged steroid use is required, with more than $50 \%$ of patients continuing immunosuppression beyond 2 years. There is no standard second-line therapy for cGVHD. Many agents have been reported in small case series, but the studies are heterogeneous in patient selection and response criteria. There is a need for a systematic study of agents for secondary therapy of cGVHD. In addition, both cGVHD and its treatment are associated with severe complications, including life-threatening infections, reduced quality of life, and psychosocial disturbances. A multidisciplinary approach to evaluating and managing patients with cGVHD is preferred, and disciplined, prospective study of new therapies is essential to make further progress in its understanding and treatment.
\end{abstract}

\section{Keywords}

cGVHD; chronic graft versus host disease; therapy; BMT

Chronic graft-versus-host disease (cGVHD) is an important cause of late morbidity and mortality following allogeneic hematopoietic-cell transplant (HCT). Traditionally, corticosteroids along with calcineurin inhibitors have been the mainstay of therapy for cGVHD. However, recently there has been renewed interest in treatment of this disease, and several new agents have been evaluated for treatment of primary or steroid-refractory disease.

\section{PRIMARY TOPICAL THERAPY}

Where possible, limited cGVHD has been treated with topical agents. Topical steroids for focal skin involvement, ophthalmic preparations of steroids and cyclosporine, oral solutions of locally active steroids for oral involvement, and topical estrogen creams for vaginal involvement have shown efficacy in limited disease.

\section{INITIAL SYSTEMIC THERAPY}

A combination of prednisone with cyclosporine has been the standard initial therapy for cGVHD. This is based on a study published in $1981,{ }^{1}$ where overall survival following combination therapy was superior to prednisone alone or no treatment for cGVHD. In a subsequent study, improved survival was seen following treatment with cyclosporine along

*Tel.: +1-612-624-3101; Fax: +1-612-625-6919. arora005@umn.edu.

Publisher's Disclaimer: This is a PDF file of an unedited manuscript that has been accepted for publication. As a service to our customers we are providing this early version of the manuscript. The manuscript will undergo copyediting, typesetting, and review of the resulting proof before it is published in its final citable form. Please note that during the production process errors may be discovered which could affect the content, and all legal disclaimers that apply to the journal pertain. 
with prednisone in patients with high-risk disease (platelet count $<100,000 / \mu \mathrm{L}$ ). ${ }^{2}$ However, in a more recent randomized comparison of cyclosporine and prednisone versus prednisone alone for initial therapy of cGVHD in patients with platelet count $>100,000 / \mu \mathrm{L},{ }^{3}$ similar rates of discontinuation of immunosuppression, requirements of secondary immunosuppressive therapy, transplant-related mortality and overall mortality were seen. The median duration of therapy with corticosteroids and prednisone was 1.6 years, and only $54 \%$ successfully discontinued immunosuppression by 5 years. In this study, prednisone was initiated at a dose of $1 \mathrm{mg} / \mathrm{kg} / \mathrm{day}$ along with daily cyclosporine at $10 \mathrm{mg} / \mathrm{kg} / \mathrm{day}$ divided into two doses based on ideal or actual body weight, whichever was lower. After 2 weeks, in responsive patients the dose was tapered by $25 \%$ per week on alternate days until prednisone was administered at 1 $\mathrm{mg} / \mathrm{kg}$ every other day. Response to treatment was evaluated at 8, 20 and 40 weeks. After 20 weeks, a second taper was initiated at $25 \%$ per week for 2 weeks to maintain $0.5 \mathrm{mg} / \mathrm{kg}$ on alternate days, followed by a reduction in the dose of cyclosporine to reach half of the initial daily dose until 40 weeks. Slow tapering of prednisone and cyclosporine was scheduled in the case of complete response after 40 weeks.

Most studies have evaluated survival and response to treatment as the primary endpoints. In two studies from the University of Minnesota, ${ }^{4,5}$ response rates (complete plus partial response) were 51-72\% at 1 year, with more responsive disease being reported after transplant using cord blood compared to adult unrelated donor grafts. Overall survival was 50-74\% at 4 years, with most deaths occurring due to secondary infections. Other studies have evaluated duration of steroid use and time to discontinuation of immunosuppression in these patients. Prolonged steroid use has been reported in most studies, with less than $50 \%$ discontinuing immunosuppression after 2 years. ${ }^{3-5}$

Use of thalidomide in initial therapy has been tested in two randomized trials. ${ }^{6,7}$ In both, no clinical benefit was observed when thalidomide was added to prednisone and calcineurin inhibitor. Its use was associated with a significant increase in side-effects including neutropenia and neurological toxicity.

Two ongoing randomized, double-blind, multicenter trials are testing newer agents hydroxycholoroquine (principal investigator: A.L. Gilman, University of North Carolina, Chapel Hill, USA) or mycophenolate mofetil (principal investigator: Paul Martin, Fred Hutchinson Cancer Research Center, Seattle, USA) - added to the standard treatment to improve outcomes in cGVHD.

\section{SALVAGE THERAPY}

There is no standard second-line therapy for patients with cGVHD who have failed steroid therapy. Several agents have been tested in case series and small phase-II trials; however, the studies are heterogeneous in patient population selection and definition of response criteria. The National Institutes of Health (NIH) Consensus working group has proposed incorporation of newer, more objective measures of patient selection for trials, as well as definition of response. This should improve the quality and comparability of data of studies testing salvage therapy for cGVHD.

\section{Mycophenolate mofetil}

A commonly used agent for steroid-refractory cGVHD is mycophenolate mofetil (MMF). In a study reported by Lopez et al, ${ }^{8} 75 \%$ and $90 \%$ of patients receiving MMF as therapy for refractory cGVHD or as primary therapy (with cyclosporine and prednisone) had an objective response. The overall survival was $85 \%$ at 2 years. Baudard et $\mathrm{al}^{9}$ reported a similar high response rate of $69 \%$, but reported higher rates of opportunistic infections in these patients. Higher serum trough levels of mycophenolate mofetil active metabolite, mycophenolic acid, 
were associated with an improved response rate. Busca et al ${ }^{10}$ reported a response rate of $60 \%$ after a median of 4 months of therapy in 15 children. Krejci et al ${ }^{11}$ reported seven responses in 11 patients treated for refractory cGVHD. Kim et al ${ }^{12}$ reported ten responses among 13 patients with cGVHD previously treated with cyclosporine and prednisone (eight patients) or prednisone alone (five patients), and reported an overall survival of $54 \%$ at 2 years. Mookerjee et al ${ }^{13}$ reported a $46 \%$ response rate among 26 patients with refractory cGVHD treated with MMF and tacrolimus.

\section{Rituximab}

B cells may be implicated in the pathogenesis of cGVHD, as is evidenced by antibody production against sex-mismatched, Y-chromosome-encoded minor HLA antigens in association with cGVHD. Rituximab has been investigated in a small number of patients with refractory cGVHD using a standard regimen of $375 \mathrm{mg} / \mathrm{m}^{2}$ for 4 weeks. Ratanatharathorn et $\mathrm{al}^{14}$ documented response in four of eight patients with sclerodermoid skin disease. Similarly Canninga Van Dijk et a $1^{15}$ and Okamoto et $\mathrm{al}^{16}$ reported improvement after treatment with rituximab. Cutler et a ${ }^{17}$ tested rituximab in a phase-I/II study in refractory cGVHD. Twentyone patients were treated with 38 cycles of rituximab. The drug was well tolerated, and toxicity was limited to infectious events. The clinical response rate was $70 \%$. However, responses were limited to patients with cutaneous and musculoskeletal manifestations of cGVHD. The median dose of prednisone was reduced from $40 \mathrm{mg} /$ day to $10 \mathrm{mg} /$ day by 1 year after rituximab therapy. Antibody titers against $\mathrm{Y}$-chromosome-encoded minor HLA antigens fell and remained low, whereas titers against infectious antigens -Epstein-Barr virus (EBV), tetanus - remained stable or rose during the treatment period. The results of these preliminary studies highlight the potential activity of rituximab against some GVHD manifestations, with a particularly high efficacy for skin involvement, including scleroderma.

\section{Sirolimus}

Sirolimus is a macrocyclic triene antibiotic with immunosuppressive, antitumor and antifungal properties. Sirolimus prevents T- and B-cell activation by cytokines which in turn prevents cell-cycle progression and cell proliferation. Efficacy of sirolimus in combination with tacrolimus and methylprednisone was tested in a phase-II trial by Couriel et al, ${ }^{18}$ who studied 35 patients with refractory cGVHD. The overall response rate was 63\%. Major adverse events related to the combination of sirolimus and tacrolimus were hyperlipidemia, renal dysfunction, cytopenias and infectious complications. Thrombotic microangiopathy was seen in four cases. In another study by Jurado et al, ${ }^{19} 47$ patients with relapsed or refractory cGVHD were treated with a combination of sirolimus and calcineurin inhibitor $(\mathrm{n}=33)$, mycophenolate mofetil $(\mathrm{n}$ $=9$ ) or prednisone $(n=5)$. A clinical response was seen in $81 \%$. The main toxicity was mild renal insufficiency. Four patients developed thrombotic microangiopathy which was treated with discontinuation of sirolimus and calcineurin inhibitors plus plasmapheresis. Johnston et $\mathrm{al}^{20}$ reported that 15 of 16 evaluable patients with refractory cGVHD demonstrated a clinical response to sirolimus in combination with prednisone and calcineurin inhibitors. The most important toxicity observed in all these studies was renal insufficiency and thrombotic microangiopathy, which was probably related to higher sirolimus levels that exaggerate the vascular toxicity of calcineurin inhibitors. When used together, serum levels of both agents must be monitored carefully and maintained in a low therapeutic range.

\section{Extracorporeal photopheresis (ECP)}

$\mathrm{ECP}$ is a technique where lymphocytes collected by a process of apheresis are exposed to psoralen and UVA treatment (PUVA). Various mechanisms have been proposed to explain the efficacy of ECP and ultraviolet light in the treatment of cGVHD, including induction of lymphocyte apoptosis, changes in dendritic-cell (DC) differentiation and function, induction 
of regulatory T-cell subsets, synthesizing interleukin 10 (IL-10), and in the long term, restoration of the DCI/DC2 and T helper 1 (Th1)/Th2 balance in favor of DC2/Th2. ${ }^{21}$ Several retrospective and prospective studies have shown activity of ECP in the management of cGVHD. Greinix et al ${ }^{22}$ treated 15 patients with refractory cGVHD and reported responses in $80 \%$ in skin, $70 \%$ in liver, and all of the patients with involvement of oral mucosa.

Apisarnthanarax et $\mathrm{al}^{23}$ reported $56 \%$ responses in 32 patients with cGVHD of the skin, with responses in both lichenoid and sclerodermal forms. Foss et $\mathrm{al}^{24}$ prospectively enrolled 25 patients with steroid-refractory cGVHD into a trial evaluating the efficacy of ECP. In all, 20 patients had improvement in skin cGVHD, and six had healing of oral ulcers. In a report from the European Group for Blood and Marrow Transplantation (Kanold et al), ${ }^{25} 63$ pediatric patients were treated with ECP. The overall response was 63\%. Maximum frequency of response was noted in skin disease followed by liver, gut and lung disease. In a report by Couriel et al, ${ }^{21} 71$ patients with steroid-resistant cGVHD were treated with ECP. All patients initiated therapy with two to four treatments per week, tapered when partial response was observed. Treatments were then decreased by one per week, and subsequently patients were placed on a maintenance regimen of two treatments every 2 weeks. Patients received a median of $32 \mathrm{ECP}$ procedures (range 1-259) over a median of 14.5 weeks (range 1-333 weeks). The overall response rate was $61 \%$, with response rates of $59 \%$ in skin disease, $71 \%$ in liver disease, $77 \%$ in oral mucosa, $67 \%$ in eyes, and $54 \%$ in bronchiolitis obliterans. The procedure overall was well tolerated, and toxicities reported were mild and reversible, and did not require discontinuation of ECP. These results support responsiveness of both skin and visceral disease in ECP.

\section{High-dose steroids}

Pulsed high-dose steroids are postulated to have a lympholytic role, with the goal being destruction of as many effector lymphocytes as possible before target tissue damage occurs. In a study by Akpek et al, ${ }^{26} 61$ patients with severe refractory cGVHD were treated with a high-dose pulse steroid regimen with methylprednisone at $10 \mathrm{mg} / \mathrm{kg} /$ day for 4 consecutive days, with subsequent tapering doses. A major response was seen in $48 \%$ of patients, $27 \%$ showed a minor response. The treatment was well tolerated with no serious adverse events.

\section{Pentostatin}

In a report by Jacobsohn et al, ${ }^{27} 58$ patients with steroid-refractory cGVHD were given pentostatin $4 \mathrm{mg} / \mathrm{m}^{2}$ intravenously every 2 weeks for 12 doses. Of 58 patients, $32(55 \%)$ had an objective response. Infection was the most significant toxicity, with 11 grade-III-IV infectious events.

\section{Daclizumab}

Daclizumab functions as an IL-2-receptor antagonist, inhibiting IL-2-mediated stimulation of lymphocytes. In a report by Willenbacher et al, ${ }^{28}$ four patients with refractory cGVHD were treated with daclizumab. Response was seen in three patients. Infections were the main sideeffect.

\section{Etanercept}

Etanercept is a recombinant soluble tumor necrosis factor (TNF) receptor fusion protein that blocks the binding of TNF to cell-surface receptors and therefore modulates the inflammatory and immune responses exerted by TNF. Chiang et $\mathrm{al}^{29}$ evaluated the efficacy of etanercept in steroid-refractory cGVHD in ten patients. Etanercept was given twice weekly for 4 weeks, followed by once weekly for 4 more weeks. Seven of eight patients who finished treatment showed improvement. 


\section{Oral beclomethasone}

This is an enteric coated oral formulation of corticosteroid beclomethasone, and may have some topical activity in gastrointestinal GVHD. Fifteen patients with gastrointestinal GVHD refractory to systemic corticosteroids were treated with a 28-day course of oral beclomethasone. ${ }^{30}$ Nine patients responded, but required multiple cycles of therapy (median three). Suppression of the adrenal-hypothalamic axis was seen in two of the five patients tested. A more recent randomized placebo-controlled trial tested the drug in acute gastrointestinal GVHD $;{ }^{30} 130$ patients were randomized to receive oral beclomethasone versus placebo. There was a reduction in the risk of treatment failure (though not statistically significant) at day 50.

\section{Thalidomide}

Thalidomide has known immunomodulatory properties and has been used in the treatment of refractory cGVHD. In a trial of thalidomide in 37 patients with steroid-refractory disease, ${ }^{31}$ $38 \%$ of patients responded, and $41 \%$ were alive after 2 years from initiation of therapy. Another study evaluated 80 patients with refractory GVHD; ${ }^{32} 20 \%$ of patients responded, but $36 \%$ had to have the medication discontinued because of side-effects which included sedation, constipation, neuritis, skin rash, and neutropenia.

Other strategies that have been reported include pulse cyclophosphamide, ${ }^{33}$ clofazimine, ${ }^{34}$ etretinate, ${ }^{35}$ total lymphoid irradiation, ${ }^{36}$ and mesenchymal stem-cell infusion. ${ }^{37}$

\section{SUPPORTIVE CARE}

A multidisciplinary approach to management of patients with cGVHD is needed. Potential side-effects of treatment include infections, osteoporosis, hypertension, hyperglycemia, renal insufficiency, and hyperlipidemia. In addition, the disease is associated with reduced quality of life and psychosocial disturbances. Appropriate care of these patients requires antimicrobial prophylaxis against encapsulated bacteria, pneumocystis pneumonia, cytomegalovirus, varicella zoster and herpes simplex viruses (in patients at risk), and antifungal prophylaxis. Considerable attention and subspecialty opinion may be required for management of these patients.

\section{SUMMARY}

Several agents have been tried in steroid-refractory or steroid-dependent cGVHD (Table 1). However, the data are difficult to interpret due to heterogeneous patient populations, retrospective study designs, small sample sizes, and inconsistent definitions of response. Definitive evaluation of salvage therapy for cGVHD requires prospective controlled studies. A prospective multicenter phase-II randomized trial in patients with cGVHD responsive to initial therapy is planned through the Blood and Marrow Transplant Clinical Trials Network (BMT CTN).

\section{Practice points}

- cGVHD is a common complication after HCT and is a leading cause of late cGVHD relapse mortality

- standard therapy consists of steroids along with a calcineurin inhibitor

- prolonged steroid use is required, with $<50 \%$ discontinuing immunosuppression by 2 years

- there is no standard salvage therapy for cGVHD; several agents have been tested in small case series, with response rates of $20-80 \%$ 
- the disease and its treatment are associated with severe complications including infections, osteoporosis, hypertension, hyperglycemia, renal insufficiency and hyperlipidemia

- infections are the leading cause of death in patients with cGVHD, hence antimicrobial prophylaxis is required

- careful attention to and management of complications may require subspecialty opinion

\section{Research agenda}

- two recent randomized double-blind multi-center trials are testing newer agents hydroxychloroquine (principal investigator: A.L. Gilman, University of North Carolina, Chapel Hill) and mycophenolate mofetil (principal investigator: Paul Martin, Fred Hutchinson Cancer Research Center, Seattle) - added to standard treatment to improve outcomes in cGVHD

- a phase-II randomized trial in patients non-responsive to initial therapy testing sirolimus and ECP is planned through the Blood and Marrow Transplant Clinical Trials Network (BMT CTN)

\section{References}

1. Sullivan KM, Shulman HM, Storb R, et al. Chronic graft-versus-host disease in 52 patients: adverse natural course and successful treatment with combination immunosuppression. Blood 1981;57:267276. [PubMed: 7004534]

2. Sullivan KM, Witherspoon RP, Storb R, et al. Alternating-day cyclosporine and prednisone for treatment of high-risk chronic graft-v-host disease. Blood 1988;72:555-561. [PubMed: 3042042]

3. Koc S, Leisenring W, Flowers ME, et al. Therapy for chronic graft-versus-host disease: a randomized trial comparing cyclosporine plus prednisone versus prednisone alone. Blood 2002;100:48-51. [PubMed: 12070007]

4. Arora M, Burns LJ, Davies SM, et al. Chronic graft-versus-host disease: a prospective cohort study. Biol Blood Marrow Transplant 2003;9:38-45. [PubMed: 12533740]

5. Arora M, Nagaraj S, Wagner JE, et al. Chronic graft-versus-host disease (cGVHD) following unrelated donor hematopoietic stem cell transplantation (HSCT): higher response rate in recipients of unrelated donor (URD) umbilical cord blood (UCB). Biol Blood Marrow Transplant 2007;13:1145-1152. [PubMed: 17889350]

6. Arora M, Wagner JE, Davies SM, et al. Randomized clinical trial of thalidomide, cyclosporine, and prednisone versus cyclosporine and prednisone as initial therapy for chronic graft-versus-host disease. Biol Blood Marrow Transplant 2001;7:265-273. [PubMed: 11400948]

7. Koc S, Leisenring W, Flowers ME, et al. Thalidomide for treatment of patients with chronic graftversus-host disease. Blood 2000;96:3995-3996. [PubMed: 11090092]

8. Lopez F, Parker P, Nademanee A, et al. Efficacy of mycophenolate mofetil in the treatment of chronic graft-versus-host disease. Biol Blood Marrow Transplant 2005;11:307-313. [PubMed: 15812396]

9. Baudard M, Vincent A, Moreau P, Kergueris MF, Harousseau JL, Milpied N. Mycophenolate mofetil for the treatment of acute and chronic GVHD is effective and well tolerated but induces a high risk of infectious complications: a series of $21 \mathrm{BM}$ or PBSC transplant patients. Bone Marrow Transplant 2002;30:287-295. [PubMed: 12209350]

10. Busca A, Saroglia EM, Lanino E, et al. Mycophenolate mofetil (MMF) as therapy for refractory chronic GVHD (cGVHD) in children receiving bone marrow transplantation. Bone Marrow Transplant 2000;25:1067-1071. [PubMed: 10828867]

11. Krejci M, Doubek M, Buchler T, Brychtova Y, Vorlicek J, Mayer J. Mycophenolate mofetil for the treatment of acute and chronic steroid-refractory graft-versus-host disease. Ann Hematol 2005;84:681-685. [PubMed: 16001244] 
12. Kim JG, Sohn SK, Kim DH, et al. Different efficacy of mycophenolate mofetil as salvage treatment for acute and chronic GVHD after allogeneic stem cell transplant. Eur J Haematol 2004;73:56-61. [PubMed: 15182339]

13. Mookerjee B, Altomonte V, Vogelsang G. Salvage therapy for refractory chronic graft-versus-host disease with mycophenolate mofetil and tacrolimus. Bone Marrow Transplant 1999;24:517-520. [PubMed: 10482936]

14. Ratanatharathorn V, Carson E, Reynolds C, et al. Anti-CD20 chimeric monoclonal antibody treatment of refractory immune-mediated thrombocytopenia in a patient with chronic graft-versus-host disease. Ann Intern Med 2000;133:275-279. [PubMed: 10929168]

15. Canninga-van Dijk MR, van der Straaten HM, Fijnheer R, Sanders CJ, van den Tweel JG, Verdonck LF. Anti-CD20 monoclonal antibody treatment in 6 patients with therapy-refractory chronic graftversus-host disease. Blood 2004;104:2603-2606. [PubMed: 15251978]

16. Okamoto M, Okano A, Akamatsu S, et al. Rituximab is effective for steroid-refractory sclerodermatous chronic graft-versus-host disease. Leukemia 2006;20:172-173. [PubMed: 16239908]

17. Cutler C, Miklos D, Kim HT, et al. Rituximab for steroid-refractory chronic graft-versus-host disease. Blood 2006;108:756-762. [PubMed: 16551963]

18. Couriel DR, Saliba R, Escalon MP, et al. Sirolimus in combination with tacrolimus and corticosteroids for the treatment of resistant chronic graft-versus-host disease. Br J Haematol 2005;130:409-417. [PubMed: 16042691]

19. Jurado M, Vallejo C, Perez-Simon JA, et al. Sirolimus as part of immunosuppressive therapy for refractory chronic graft-versus-host disease. Biol Blood Marrow Transplant 2007;13:701-706. [PubMed: 17531780]

20. Johnston LJ, Brown J, Shizuru JA, et al. Rapamycin (sirolimus) for treatment of chronic graft-versushost disease. Biol Blood Marrow Transplant 2005;11:47-55. [PubMed: 15625544]

21. Couriel DR, Hosing C, Saliba R, et al. Extracorporeal photochemotherapy for the treatment of steroidresistant chronic GVHD. Blood 2006;107:3074-3080. [PubMed: 16368882]

22. Greinix HT, Volc-Platzer B, Rabitsch W, et al. Successful use of extracorporeal photochemotherapy in the treatment of severe acute and chronic graft-versus-host disease. Blood 1998;92:3098-3104. [PubMed: 9787144]

23. Apisarnthanarax N, Donato M, Korbling M, et al. Extracorporeal photopheresis therapy in the management of steroid-refractory or steroid-dependent cutaneous chronic graft-versus-host disease after allogeneic stem cell transplantation: feasibility and results. Bone Marrow Transplant 2003;31:459-465. [PubMed: 12665841]

24. Foss FM, DiVenuti GM, Chin K, et al. Prospective study of extracorporeal photopheresis in steroidrefractory or steroid-resistant extensive chronic graft-versus-host disease: analysis of response and survival incorporating prognostic factors. Bone Marrow Transplant 2005;35:1187-1193. [PubMed: 15852025]

25. Kanold J, Messina C, Halle P, et al. Update on extracorporeal photochemotherapy for graft-versushost disease treatment. Bone Marrow Transplant 2005;35 (Suppl 1):S69-71. [PubMed: 15812535]

26. Akpek G, Lee SM, Anders V, Vogelsang GB. A high-dose pulse steroid regimen for controlling active chronic graft-versus-host disease. Biol Blood Marrow Transplant 2001;7:495-502. [PubMed: 11669216]

27. Jacobsohn DA, Chen AR, Zahurak M, et al. Phase II study of pentostatin in patients with corticosteroid-refractory chronic graft-versus-host disease. J Clin Oncol 2007;25:4255-4261. [PubMed: 17878478]

28. Willenbacher W, Basara N, Blau IW, Fauser AA, Kiehl MG. Treatment of steroid-refractory acute and chronic graft-versus-host disease with daclizumab. Br J Haematol 2001;112:820-823. [PubMed: 11260089]

29. Chiang KY, Abhyankar S, Bridges K, Godder K, Henslee-Downey JP. Recombinant human tumor necrosis factor receptor fusion protein as complementary treatment for chronic graft-versus-host disease. Transplantation 2002;73:665-667. [PubMed: 11889452] 
30. Hockenbery DM, Cruickshank S, Rodell TC, et al. A randomized, placebo-controlled trial of oral beclomethasone dipropionate as a prednisone-sparing therapy for gastrointestinal graft-versus-host disease. Blood 2007;109:4557-4563. [PubMed: 17244684]

31. Browne PV, Weisdorf DJ, DeFor T, et al. Response to thalidomide therapy in refractory chronic graftversus-host disease. Bone Marrow Transplant 2000;26:865-869. [PubMed: 11081386]

32. Parker PM, Chao N, Nademanee A, et al. Thalidomide as salvage therapy for chronic graft-versushost disease. Blood 1995;86:3604-3609. [PubMed: 7579470]

33. Mayer J, Krejci M, Doubek M, et al. Pulse cyclophosphamide for corticosteroid-refractory graftversus-host disease. Bone Marrow Transplant 2005;35:699-705. [PubMed: 15696180]

34. Lee SJ, Wegner SA, McGarigle CJ, Bierer BE, Antin JH. Treatment of chronic graft-versus-host disease with clofazimine. Blood 1997;89:2298-2302. [PubMed: 9116272]

35. Marcellus DC, Altomonte VL, Farmer ER, et al. Etretinate therapy for refractory sclerodermatous chronic graft-versus-host disease. Blood 1999;93:66-70. [PubMed: 9864147]

36. Socie G, Devergie A, Cosset JM, et al. Low-dose (one gray) total-lymphoid irradiation for extensive, drug-resistant chronic graft-versus-host disease. Transplantation 1990;49:657-658. [PubMed: 2316026]

37. Ringden O, Uzunel M, Rasmusson I, et al. Mesenchymal stem cells for treatment of therapy-resistant graft-versus-host disease. Transplantation 2006;81:1390-1397. [PubMed: 16732175] 


\section{Table 1}

Selected phase-II studies of novel agents in chronic graft-versus-host disease (cGVHD).

\begin{tabular}{|c|c|c|c|}
\hline Study & Novel therapy & Sample size & e Response \\
\hline Lopez et al ${ }^{8}$ & MMF & 24 & $75 \%$ \\
\hline Baudard et al $^{9}$ & MMF & 15 & $69 \%$ \\
\hline Busca et al ${ }^{10}$ & MMF & 15 & $60 \%$ \\
\hline Krejci et al ${ }^{11}$ & MMF & 11 & $64 \%$ \\
\hline Kim et al ${ }^{12}$ & MMF & 13 & $77 \%$ \\
\hline Mookeriee et al ${ }^{13}$ & MMF & 26 & $46 \%$ \\
\hline Ratanathorn et al ${ }^{14}$ & Rituximab & 8 & $50 \%$ \\
\hline Canniga Van Dijk et al ${ }^{15}$ & Rituxumab & 6 & $83 \%$ \\
\hline Cutler et al ${ }^{17}$ & Rituximab & 21 & $70 \%$ \\
\hline Couriel et al ${ }^{18}$ & Sirolimus & 35 & $63 \%$ \\
\hline Jurado et al ${ }^{19}$ & Sirolimus & 47 & $81 \%$ \\
\hline Johnston et $\mathrm{al}^{20}$ & Sirolimus & 16 & $93 \%$ \\
\hline Greinix et al ${ }^{22}$ & ECP & 15 & $80 \%$ (skin) \\
\hline Apisarnthanarax et $\mathrm{al}^{23}$ & ECP & 32 & $56 \%$ (skin) \\
\hline Foss et $\mathrm{al}^{24}$ & ECP & 25 & $80 \%$ (skin) \\
\hline Kanold et al 25 & ECP & 63 & $63 \%$ \\
\hline Couriel et al ${ }^{21}$ & ECP & 71 & $61 \%$ \\
\hline Akpek et al ${ }^{26}$ & Pulsed steroids & 61 & $75 \%$ \\
\hline Jacobsohn et $\mathrm{al}^{27}$ & Pentostatin & 58 & $55 \%$ \\
\hline Willenbacher et $\mathrm{al}^{28}$ & Daclizumab & 4 & $75 \%$ \\
\hline Chiang et $\mathrm{al}^{29}$ & Etanercept & 10 & $70 \%$ \\
\hline Browne et al ${ }^{31}$ & Thalidomide & 37 & $38 \%$ \\
\hline Parker et al ${ }^{32}$ & Thalidomide & 80 & $20 \%$ \\
\hline
\end{tabular}

MMF, mycophenolate mofetil; ECP. extracorporeal photopheresis. 